\title{
Predictive modelling applied to the retention of mortgages
}

Received: 4th September, 2002

\section{Leonard Paas}

worked for several years at the Database Marketing Centre of the Postbank in The Netherlands. He worked on issues such as data mining, prospect selection, predictive modelling, segmentation, lifetime value and credit scoring. He has conducted similar work as a consultant. Leonard received his PhD at Tilburg University and now works as an Assistant Professor in the Department of Marketing at Tilburg University.

\begin{abstract}
The mortgage is potentially one of the most profitable products in the financial services sector. The costs involved in selling mortgages are, however, high, thus profits are only made if mortgage contracts are not transferred after just a short period. As a result of the decrease in interest rates in the 1990s clients do often transfer mortgages that were acquired at a time when interest rates were higher, because they can realise a lower interest rate by doing so. There are other reasons for transferring a mortgage, eg on the advice of a sales representative working for a competitor or because of dissatisfaction with the service of the current mortgage provider. Therefore, techniques that can support marketing strategies aimed at the retention of mortgage contracts are useful for this business sector. This paper discusses building models to support such strategies and techniques for testing strategies for mortgage retention. The propositions are illustrated using hypothetical examples, clarifying how practitioners can implement the proposed approaches towards the retention of mortgages.
\end{abstract}

\section{INTRODUCTION}

Retention concerns strategies aimed at retaining existing customers. This issue is particularly relevant for the financial services sector, because in this sector it is substantially cheaper to keep an existing client than to convert prospects into new clients. ${ }^{1,2}$ For mortgages these

considerations are probably more relevant than for any other financial service. This is due to the high costs involved in selling a mortgage. First of all, the costs involved in marketing this product are high. Prospects do not acquire a mortgage after receiving a single mailing or after reading one advertisement. The acquisition of a mortgage is usually the most important financial decision a consumer makes, therefore, much information is required before a decision is made. ${ }^{3}$ Secondly, there are multiple administrative tasks involved in the sale of a mortgage, which also implies that the provider of the mortgage incurs costs. Last, but certainly not least, a sales representative or intermediary often receives a large commission for each mortgage sold. This commission usually has to be subtracted from the profit made by the financial services provider on the mortgage. These considerations indicate that the retention of mortgages is an important issue.

For retention purposes it is necessary to have insight into the probability of a client transferring her/his mortgage to a 
competitor. If such information is available marketing strategies can be formulated for customer segments that are relatively likely to display this behaviour. The current study concentrates on the utilisation of predictive modelling techniques for the purpose of segmenting mortgage users with regard to the probability of transferring their mortgage to a competitor. Furthermore, the development of marketing strategies aimed at retention of mortgage contracts is discussed.

In the next section, the use of predictive modelling for the purpose of allocating transfer probabilities to subjects is discussed. Then a method is proposed that is suitable for building such models. There follows a discussion on the use of mortgage retention models for supporting marketing strategies and on testing the effectiveness of such strategies. The paper concludes with a discussion.

\section{USING PREDICTIVE MODELLING FOR THE RETENTION OF MORTGAGES}

Mortgage contracts are usually intended to run for a set period. Nevertheless, the contract can be ended earlier than planned. For example, the consumer can pay the provider of the mortgage a cash-out fee. Other possibilities are that the client sells the house for which the mortgage was acquired or the contract ends when the client dies. For the purposes of this paper it is only relevant to predict the probability of contract termination which can be prevented by the supplier of the mortgage.

For practical purposes, a preventable contract termination is defined as a transfer of the mortgage to a competitor. This transfer may, for example, take place after a cash-out fee has been paid, or may follow sale of the house for which the mortgage was acquired or a transfer may take place after the contract period has ended. In all cases it is possible to speak of a preventable termination of the mortgage relation with a client if this client ends the contract and acquires a new mortgage from a competitor. If a new mortgage is acquired it is clear that the client still needs a mortgage. This also applies if the house for which the mortgage was acquired is sold. If the first house is sold and a new house is purchased using a mortgage acquired from a competitor, then the supplier of the first mortgage has obviously lost a client. If the mortgage provider could have made an acceptable offer or could have delivered satisfactory service on the old contract, the client might not have transferred the mortgage to a competitor.

Predictive modelling concerns the utilisation of statistical techniques and procedures for the purpose of determining the probability of a specific behaviour being displayed. Predictive modelling has previously been used to predict the occurrence of various types of behaviour. The most common application is the utilisation for prospect selection purposes. ${ }^{4,5}$ In this case predictive modelling is used to allocate response probabilities to different types of subjects. These response probabilities indicate how great the probability is that a subject will respond to a specific mail offer in a previously determined time span. Another common application of predictive modelling is credit scoring. ${ }^{6}$ Credit scoring is relevant for companies offering personal loans and is intended to support estimation of the probability that each subject will pay off the borrowed money in a satisfactory manner.

Predictive modelling techniques can also be utilised to determine probabilities that different types of subjects will transfer their existing mortgages to a competitor. To build this type of model 
a data set of a specific moment in time, containing information on mortgage clients is required. Furthermore, the utilised data set should also contain a variable indicating whether the client has transferred the mortgage in a specified period. For example, consider a data set containing the values clients have on relevant variables in December, 2000. This data set also has to contain a variable that indicates whether a subject transferred the existing contract in 2001. In this case the values subjects have on the variables of December, 2000 are used to predict whether the mortgage is transferred in 2001.

If the situation in the market does not change substantially, then the model can also be applied, in for example, December, 2001 to indicate which subjects are most likely to transfer their mortgage in 2002. Of course, the model has to be monitored in the same way as other types of predictive models. ${ }^{7}$ When applied to mortgage transfer models, monitoring should aim to test whether a model still distinguishes subjects that are likely to transfer their mortgage from other clients. If this distinction is no longer made then an updated model has to be built. Such updates usually have to be made three or four times a decade.

\section{FACTORS PREDICTING MORTGAGE TRANSFER}

If predictive models are used for prospect selection purposes or for credit scoring then clients' characteristics are usually the most important factors influencing the modelled behaviour. For example, a subject's age and income are important factors when determining whether a subject will pay back a loan in an acceptable manner. For a model predicting the probability that a subject will transfer a mortgage such variables can also play an important role. It is however, likely that other factors are more important for a mortgage transfer model. Such factors are reviewed below and should be available when building a model to predict the probability that a mortgage is transferred.

The most important factors influencing the probability that subjects will transfer their mortgages are related to an event occurring at one specific point in time and can, therefore, be referred to as triggers. To start off, the two most important triggers concern the possibility of ending the contract without having to pay a cash-out fee. This occurs when (1) the owner sells the house for which the mortgage is utilised and (2) when reaching the end of the pre-determined contract period. Determining the latter point in time is trivial, as this moment is established when the contract is signed. For the former, a model needs to be built which predicts whether a subject is likely to sell her/his house in the near future.

Other triggers can be relevant for a retention model for mortgages is affected by market trends. Changes in interest rates can be particularly important. If interest rates drop substantially then subjects may be more inclined to transfer their mortgages, because they can obtain a better rate by doing so. Another market trend could be house prices. If house prices increase subjects may be inclined to take an extra mortgage on their house to finance, for example, an extension to the house. If subjects take an extra mortgage they have a good reason to compare different mortgage interest rates (and providers) and may conclude that they can get a better rate on the mortgage than they already have. The latter may lead to a transfer. In general, it is proposed that changes in house prices will trigger subjects' interest in their houses and mortgages. 


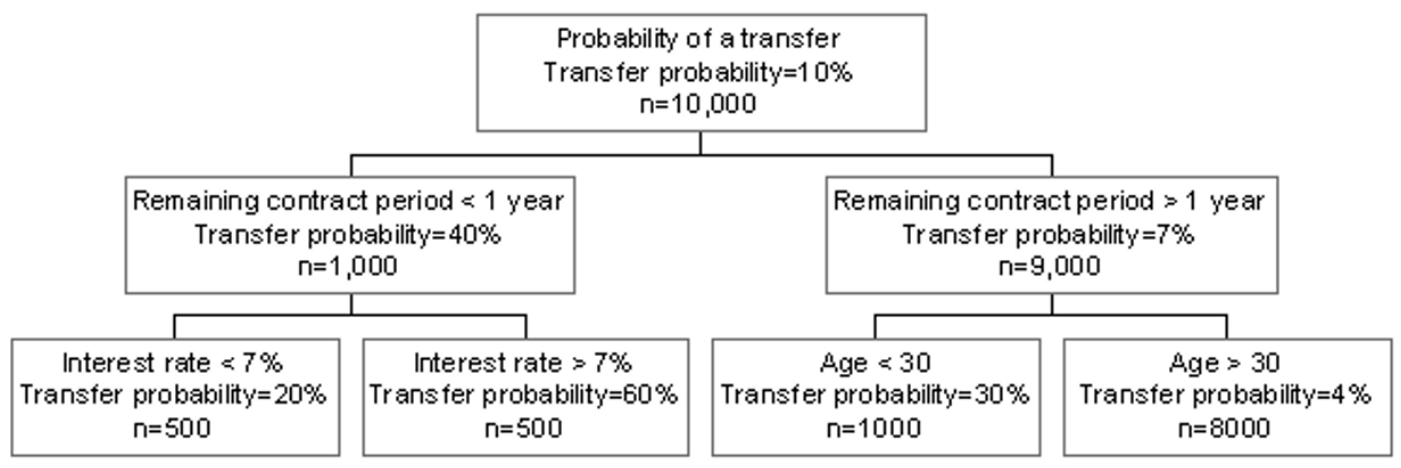

Figure 1

This interest can have consequences for the mortgage a subject owns.

\section{BUILDING THE MODEL}

A predictive modelling technique can combine the factors mentioned and other relevant information in such a manner that a probability of a mortgage transfer can be allocated to each subject at any point in time. CHAID is a suitable technique for building such a model. ${ }^{8}$ This technique can be used for modelling various different types of relations between variables, such as non-linear coherence and interaction effects. Moreover, the results of CHAID are highly transparent and, therefore, can easily be applied to support the formulation of marketing strategies. Figure 1 gives a hypothetical example of a CHAID tree that can be used to calculate probabilities that different types of subjects transfer their mortgage within a year. This hypothetical example is based on models found in real-life data of financial services providers. The combinations of variables and the specific variables included in Figure 1 are, however, also found in models based on real-life data. For example, if a consumer has a high interest rate on their mortgage and the remaining contract period is less than a year, the probability that the mortgage will be transferred to a competitor is high, as is indeed shown in Figure 1.

Figure 1 shows that subjects who have a mortgage contract that ends within a year and who pay an interest rate of at least 7 per cent have the greatest probability of transferring their mortgage, ie 60 per cent. Thus, finding marketing strategies suitable for retaining this segment of clients has the highest priority. Consecutively, the company should develop strategies suitable for retaining subjects younger than 30 years with a contract that is due to run longer than one year. Figure 1 shows that the probability that these subjects will transfer their mortgage is also high, there is a 30 per cent chance that this will happen within a year. Finally, the mortgage provider should develop strategies that aim to retain subjects owning mortgage contracts ending within a year and who pay an interest rate of less than 7 per cent. The remaining 8,000 subjects have a transfer probability of 4 per cent within a year. It is unlikely that it is necessary to develop strategies aimed at retaining these clients. First of all their transfer rate is quite low. More importantly, given the low transfer rate in this segment, it is likely that these subjects will stop using the current mortgage as a result of multiple 
coincidental factors, such as death of the client, divorce, loss of employment, etc. The latter implies that marketing strategies are unlikely to have a substantial influence on the transfer percentage of this category of subjects.

\section{FORMULATING AND TESTING A SUITABLE RETENTION STRATEGY}

The discussion above implies that the model can guide a marketer when deciding which segments should be approached in campaigns aimed at the retention of mortgages. The model is also useful from another perspective, ie the characteristics of clients that are likely to transfer their mortgage, as shown in the model, can be considered as useful input for the formulation of marketing strategies. These characteristics can be regarded as hints about the motives underlying the transfer of mortgages. Sometimes these hints are difficult to interpret, but in most cases they are highly transparent. The latter also applies to the fictitious example displayed as Figure 1. As mentioned above, this CHAID model shows that subjects who have mortgage contracts that end within a year and who pay an interest rate of at least 7 per cent have the greatest probability of transferring their mortgage. This implies that subjects who can transfer their mortgage against a low cash-out fee will do so if they can obtain a lower interest rate. For a marketer this information indicates that that segment should be offered a more competitive interest rate.

Of course, in the hypothetical example, a calculation has to be made as to whether the profits resulting from customer retention are higher than the costs involved in the decrease of the interest rate. Better still, a marketer can experiment with different interest rates and estimate which interest rate leads to the greatest net profit. For the fictitious example this implies that the subjects, who have mortgage contracts that end within a year and who pay an interest rate of at least 7 per cent, are divided into five categories, Groups 1 to 5. Each group receives a different offer:

- Group 1 may change their interest rate from 7 per cent to 6.5 per cent without paying a cash-out fee, change in interest rate $=0.5$ per cent

- Group 2 may change their interest rate from 7 per cent to 6 per cent without paying a cash-out fee, change in interest rate $=1$ per cent

- Group 3 may change their interest rate from 7 per cent to 5.5 per cent without paying a cash-out fee, change in interest rate $=1.5$ per cent

- Group 4 may change their interest rate from 7 per cent to 5 per cent without paying a cash-out fee, change in interest rate $=2$ per cent

- Beside the four experimental groups a control group is required. This group receives no offer whatsoever. The transfer rate in the control group is a benchmark for the transfer rates in the four experimental groups. The 60 per cent displayed in Figure 1 cannot be used as such, because this figure was established at a period before the experiments were conducted. This implies the situation in the market may have changed and transfer rates may be different in the relevant segment of subjects.

After the experiment has been conducted the costs of each interest reduction should be calculated. When information on the costs is available the change in transfer rate resulting from the offer is established. The effect on the transfer rates, in each of the five groups, should be established at different points in time after the conduction of actions that are 
Table 1: Mortgage transfer rates within the different groups

\begin{tabular}{llllll}
\hline $\begin{array}{l}\text { Change in } \\
\text { interest \% }\end{array}$ & $\begin{array}{l}\text { Transfer } \\
\text { rate after } \\
\mathbf{3} \text { months } \%\end{array}$ & $\begin{array}{l}\text { Transfer } \\
\text { rate after } \\
\mathbf{6} \text { months } \%\end{array}$ & $\begin{array}{l}\text { Transfer } \\
\text { rate after } \\
\mathbf{9} \text { months } \%\end{array}$ & $\begin{array}{l}\text { Transfer } \\
\text { rate after } \\
\mathbf{1 2} \text { months \% }\end{array}$ & $\begin{array}{l}\text { Transfer } \\
\text { rate after } \\
\mathbf{1 5} \text { months \% }\end{array}$ \\
\hline 2.0 & 5 & 10 & 12 & 14 & 15 \\
1.5 & 8 & 16 & 20 & 23 & 25 \\
1.0 & 10 & 19 & 25 & 29 & 31 \\
0.5 & 15 & 28 & 38 & 46 & 49 \\
0 & 20 & 38 & 50 & 59 & 63 \\
\hline
\end{tabular}

relevant for the different marketing strategies, as shown in Table 1.

In the hypothetical example interest rate reductions have a substantial influence on the transfer rates of mortgages. The transfer rate among Group 4 subjects (change in interest rate $=2$ per cent) is only 15 per cent over a period of 15 months. As a comparison the transfer rate within the control group (change in interest rate $=0$ per cent) is 63 per cent. Thus, with a change of interest rate of 2 per cent the transfer rate within a 15 -month period is reduced by 48 per cent. Decisions concerning this interest rate reduction should be repeated in the future and should be based on a comparison between the gains of the reduced transfer rate with the loss involved in the interest reduction. Moreover, if this action is conducted in the future there should always be a small group excluded from the interest reduction, to monitor whether the transfer rate is still substantially higher within this group.

\section{DISCUSSION}

Experience shows that models predicting the transfer probabilities for different segments of subjects can be formulated using a modest number of variables. The models have proven to be stable over shorter periods of time, ie a number of months. Stability over longer periods still has to be tested. It is to be expected that the effects of client characteristics are more stable, but, as mentioned above, these effects are not as strong as the effects of mortgage characteristics and developments in the market, such as changes in interest rates. Thus, models have to be updated on a regular basis. Furthermore, the effects of different strategies still have to be tested, because it is likely that a different situation in the market calls for different strategies. In the hypothetical example a reduction in interest rate was proposed as a means to enhance retention within a specific segment of subjects. It is to be expected that such an action will have desirable results in many practical situations, but sometimes other actions may be more suitable for retention purposes. This implies that a multitude of experiments has to be conducted, before a company knows which strategy should be employed for a specific segment of subjects found in a specific situation. In this context, alternative actions for changes in interest rates should be formulated and tested. If a financial services provider has substantial experience with such tests, problems concerning the transfer of mortgages may be detected before becoming acute and a suitable retention strategy can be set up.

\section{References}

1 Reichheld, F. F. (1996) 'The loyalty effect: The hidden force behind growth, profits and lasting value', Harvard Business School Press, Boston (MA). 
2 Reichheld, F. F. and Sasser, W. E. (1990) 'Zero defections: Quality comes to services', Harvard Business Review, September-October, pp. 105-111.

3 Winer, R. S. (2001) 'A framework for customer relationship management', California Management Review, Vol. 43, pp. 89-105.

4 Kuijlen, A. A. A. (1993) 'De scenariobenadering: Een onderzoek naar complexe consumentenbeslissingen met behulp van computergestuurd enquêteren (In Dutch)', doctoral dissertation, Tilburg University.

5 David Sheppard Associates (1995) 'The new direct marketing: How to implement a profit-driven database marketing strategy', Irwin Professional Publishing, New York (NY).
6 Paas, L. and Kuijlen, T. (1998) 'Analysing generic needs through Mokken Scaling and the Multi Nominal Logit model', Journal of Targeting, Measurement and Analysis for Marketing, Vol. 7, No. 2, pp. $145-154$.

7 Council on financial competition (1996) Present at the creation: Redefining competitive advantage through data-driven marketing and management', The advisory board company, Washington DC.

8 Paas, L. (1999) 'Revenue driven direct mail campaigns', Journal of Database Marketing, Vol. 6, No. 4, pp. 321-329.

9 Magidson, J. (1993) 'SPSS for Windows: CHAID release 6.0', Statistical Innovations Inc., Belmont (MA). 